\title{
Orally administered RDP58 reduces the severity of dextran sodium sulphate induced colitis
}

\author{
R Boismenu, Y Chen, K Chou, A El-Sheikh, R Buelow
}

Ann Rheum Dis 2002;61 (Suppl II):ii 19-ii24

Oral administration of the novel anti-inflammatory peptide RDP58 markedly reduced the severity of dextran sulphate sodium (DSS) colitis as determined by clinical and quantitative histological criteria. The architecture of the colonic epithelium in DSS treated mice receiving RDP58 remained relatively normal compared with that of control DSS treated animals. 5-Bromo-2'-deoxyuridine (BrdU) labelling studies showed a pronounced inhibition of colonic epithelial cell proliferation during DSS treatment, which was partially reversed by RDP58 therapy. Remarkably, RDP58 almost completely prevented colonic epithelial cell death induced by DSS treatment. RDP58 therapy also inhibited the accumulation of neutrophils in the colon of DSS treated mice and effectively down regulated tumour necrosis factor (TNF) expression. Preservation of the intestinal mucosa by RDP58 may thus derive from its influence on TNF expression as well as additional anti-inflammatory properties. These findings indicate that RDP58 represents a new, orally available agent potentially useful in the treatment of inflammatory bowel disease.

$\mathrm{T}$ he intestinal bowel diseases (IBD), ulcerative colitis and Crohn's disease, are characterised by a chronic relapsing inflammation of the intestinal tract. ${ }^{1}$ Several studies have implicated tumour necrosis factor (TNF) as a dominant player in a cytokine network that promotes colonic inflammation and tissue damage. ${ }^{2-6}$ The view that TNF or TNF expressing cells, or both, are important in the pathogenesis of IBD is reinforced by results from clinical studies showing that anti-TNF monoclonal antibody (mAb) therapy is effective in patients with CD. ${ }^{7-11}$ The clinical response to anti-TNF mAb treatment appears to be strongly associated with histological evidence of reduced inflammation ${ }^{12}$ and mucosal healing. ${ }^{13}$ Because of observed and potential complications from systemic and repeated mAb administration, the search for alternative ways of controlling TNF expression and inflammation within the intestinal tract seems warranted.

The D-isomer peptide RDP58, previously termed Allotrap 1258 , is a new anti-inflammatory compound with several distinct activities: inhibition of TNF, interferon $\gamma$ (INF $\gamma$ ), and interleukin (IL) 12 production and modulation of haem oxygenase-1 (HO-1) expression. ${ }^{14}{ }^{15}$ Little is known about the mechanism of IFN $\gamma$ and IL12 inhibition. However, studies on the mechanism of TNF inhibition showed that RDP58 seems to act post-transcriptionally, possibly by inhibition of TNF mRNA translation. ${ }^{14}$ This activity was found to be dependent on the $3^{\prime}$ untranslated region of the TNF mRNA. ${ }^{14}$ The effect of RDP58 on HO-l expression was shown to be due to direct inhibition of HO-l enzyme activity and concomitant up regulation of HO-1 gene expression. ${ }^{15-17}$

The anti-inflammatory activity of RDP58 has been demonstrated in vivo in various animal models, including lipopolysaccharide induced septic shock, concanavalin A induced hepatitis, trinitrobenzene sulphonic acid induced colitis, IBD in non-human primates, chemotherapy induced diarrhoea, and organ transplant rejection. ${ }^{14-17}$ Here, we investigated the effects of RDP58 in the well defined dextran sulphate sodium (DSS) murine colitis model system. ${ }^{18-20}$ We found that RDP58 given orally reduced the severity of murine DSS colitis as determined by clinical and histological improvements. RDP58 treatment reduced neutrophil infiltration within the colon and blunted the increase in TNF mRNA and protein levels normally seen after DSS administration. Thus, our observations identify RDP58 as an orally active anti-inflammatory compound that may be effective in the treatment of human IBD.

\section{MATERIALS AND METHODS \\ Reagents}

RDP58 (SangStat Medical Corporation) consisting of the linear $d$-amino acid sequence rnlenlenlernlenlenlegy, where nle corresponds to norleucine, was dissolved to a final concentration of $1-2 \mathrm{mg} / \mathrm{ml}$ in distilled water containing $5 \%$ cell culture grade glucose $(\mathrm{wt} / \mathrm{vol})$.

\section{Mice}

Specific pathogen-free female C57BL/6 mice, 7-8 weeks old at the start of the experiments were obtained from the Scripps Research Institute animal facility. The animals were housed in a specific pathogen-free environment. Standard mouse chow pellets and drinking water were provided freely. All experiments were performed according to our Institutional Guidelines on Animal Care and Use.

\section{Induction of colitis}

Experimental colitis was induced by giving mice drinking water containing DSS (mol wt 40 000; ICN) at a final concentration of $2.5 \%$ (wt/vol) for six days. Groups of at least four mice were used for each experiment. Liquid consumption was monitored carefully each day to confirm that each group consumed an equivalent volume.

\section{RDP58 treatment}

Mice received RDP58 at $5 \mathrm{mg} / \mathrm{kg} /$ day by gavage or intraperitoneally in a total volume of $100 \mu \mathrm{l}$. RDP58 was given daily from the start of DSS treatment.

\section{Clinical disease activity measurements}

The severity of colitis was graded daily essentially as described previously. ${ }^{19}$ Clinical symptoms monitored included body

Abbreviations: BrdU, 5-bromo-2'-deoxyuridine; DSS, dextran sulphate sodium; ELISA, enzyme linked immunosorbent assay; $\mathrm{HO}-1$, haem oxygenase-1; HTAB, hexadecyltrimethylammonium bromide; IBD, inflammatory bowel disease; IL, interleukin; INF $\gamma$, interferon $\gamma$; mAb, monoclonal antibody; MPO, myeloperoxidase; RT-PCR, reverse transcriptase-polymerase chain reaction; TNF, tumour necrosis factor; TUNEL, Tdt mediated dUTP nick end labelling 
weight, Haemoccult positivity, gross bleeding, and stool consistency. These variables were noted at the start of the experiment and daily thereafter. The disease activity index represents the sum of the scores of the clinical symptoms monitored. Blood in faeces was detected with the Haemoccult test kit (Smith Kline Diagnostics). A minimum of 20 faecal pieces for each group was collected daily to assess occult blood and stool consistency.

\section{Macroscopic and microscopic evaluation of disease activity}

Mice were killed by $\mathrm{CO}_{2}$ euthanasia. Entire gastrointestinal tracts were removed and segments $(1-2 \mathrm{~cm})$ representing the small intestines and colons of control and experimental mice were fixed in $10 \%$ neutral buffered formalin and embedded in paraffin. Thin sections $(3-5 \mu \mathrm{m})$ were stained with periodic acid-Schiff reagent and haematoxylin. Crypt damage was measured essentially as described previously. ${ }^{19}{ }^{21}$ In brief, sections were assigned the following scores: 1 if the basal half portion of crypts was eroded; 2 if more than the basal half portion of crypts was eroded; 3 if entire crypts were eroded, but the surface epithelium remained intact; 4 if entire crypts and the surface epithelium were damaged. The final crypt damage score for each section examined was obtained by adding a value representing the percentage surface involvement: 1 for $<25 \%$; 2 for $<50 \%$; 3 for $<75 \%$; 4 for $>75 \%$.

\section{In vivo BrdU labelling}

5-Bromo-2'-deoxyuridine (BrdU; Sigma) was used to label colonic epithelial cells undergoing DNA replication. BrdU was diluted from a freshly made stock solution $(5 \mathrm{mg} / \mathrm{ml}$ in phosphate buffered saline) and used at $50 \mathrm{mg} / \mathrm{kg}$ of body weight. BrdU was given intraperitoneally to groups of 3-6 mice three times at eight hourly intervals. Mice were killed eight hours after the last injection, and colonic segments embedded in Tissue-TEK OCT compound (Sakura-Fintek, Torrance, CA) before freezing in liquid nitrogen. Tissue sections $(5 \mu \mathrm{m})$ were fixed in $70 \%$ ethanol followed by sequential treatments with $2 \mathrm{~N} \mathrm{HCl}$ and $0.1 \mathrm{M}$ borax. Slides were then incubated for one hour with a monoclonal rat antiBrdU antibody (MAS 250b; Harlan Sera-Lab, Loughborough, UK), followed by further sequential incubations with a biotinylated monoclonal mouse anti-rat IgG antibody (Jackson ImmunoResearch) and peroxidase conjugated streptavidin (Jackson ImmunoResearch). Cells labelled with BrdU were identified after incubation with a metal enhanced diaminobenzidine substrate (Pierce). Slides were counterstained with haematoxylin before examination.

\section{TUNEL assay}

The TdT mediated dUTP nick end labelling (TUNEL) assay was performed on paraffin embedded sections of colon using a commercially available kit essentially as described by the manufacturer (TdT-FragEL, Oncogene Research Products). The biotinylated nucleotides incorporating DNA were detected using a streptavidin-horseradish peroxidase conjugate and reaction with the colorimetric substrate diaminobenzidine. A light counterstaining with haematoxylin facilitated the morphological evaluation and characterisation of normal and apoptotic cells. Negative controls were generated by substituting $\mathrm{dH}_{2} \mathrm{O}$ for the TdT during the labelling step. We validated the assay by performing preliminary experiments using intestinal tissue from normal and irradiated mice.

\section{TNF detection}

Tissue segments were collected from the colon of control and experimental animals with a $3 \mathrm{~mm}$ biopsy punch (Acuderm), weighed, and cultured overnight in $1 \mathrm{ml}$ complete RPMI medium containing 10\% Ultra Low IgG FBS (Gibco/BRL). TNF protein levels were determined with a commercially available enzyme linked immunosorbent assay (ELISA) system for the measurement of murine TNF concentrations in cell culture supernatants (Quantikine M, R\&D Systems). The minimum detectable mouse TNF concentration was found to be $5 \mathrm{pg} / \mathrm{ml}$ and the colorimetric response was linear between 25 and 750 $\mathrm{pg} / \mathrm{ml}$.

Total RNA extractions were performed in TRIzol reagent (Life Technologies) as recommended by the manufacturer. For RT-PCR, cDNA synthesis was achieved using the random primer $\operatorname{pd}(\mathrm{N})_{6}$ (Pharmacia). The amplification reactions were performed with commercially available primer pairs for $\beta$-actin and TNF $\alpha$ using the suggested cycle conditions (Stratagene). DNA amplification products were analysed by agarose gel electrophoresis.

\section{Assay for myeloperoxidase activity}

Tissue myeloperoxidase (MPO) activity was used to measure neutrophil accumulation. ${ }^{22}$ In brief, colonic segments were collected with a $3 \mathrm{~mm}$ biopsy punch, weighed, and resuspended in $50 \mathrm{mM}$ phosphate buffer containing hexadecyltrimethylammonium bromide (HTAB; $5 \mathrm{mg} / \mathrm{ml}$ ) at a ratio of $2 \mathrm{ml}$ HTAB buffer per $100 \mathrm{mg}$ tissue. Colonic segments were cooled on ice, homogenised (HandiShear, VirTis), sonicated for 30 seconds, and freeze-thawed three times. The resulting lysate was centrifuged at $10000 \mathrm{~g}$ for five minutes at $4^{\circ} \mathrm{C}$. Aliquots were transferred to microtitre plates and MPO activity was assayed in HTAB buffer containing hydrogen peroxide and $o$-dianisidine. The colorimetric response was monitored at optical density $460 \mathrm{~nm}$ and stopped with $0.1 \%$ sodium azide.

\section{Statistical analysis}

Statistical differences between groups for crypt damage, BrdU incorporation, MPO activity and TNF mRNA levels were calculated using the Mann-Whitney U test. Differences in TNF protein levels between groups were calculated using the alternative Welch's test. Values of $\mathrm{p}<0.05$ were considered significant.

\section{RESULTS}

Clinical benefit of orally administered RDP58 in acute DSS colitis

C57BL/6 mice fed DSS in drinking water were monitored daily for clinical symptoms for six days. Seven days of DSS treatment caused an almost complete ulceration of C57BL/6 mouse colon with few crypts remaining. The presence of blood in the faeces was detected one to two days after the start of DSS treatment, whereas gross bleeding and diarrhoea were initially observed from day 4 . Body weight loss (>5\%) became prominent after four days of DSS treatment. All DSS treated mice developed colitis with similar temporal and disease profiles. Oral RDP58 therapy of DSS treated mice ( $5 \mathrm{mg} / \mathrm{kg} /$ day) markedly reduced disease severity (fig 1 ). This was due to reductions in occult blood, gross bleeding, and diarrhoea. RDP58 did not significantly influence DSS induced body weight loss. Three independent experiments showed that the protective effects of RDP58 were reproducible. Similar results were seen when RDP58 was given at $10 \mathrm{mg} / \mathrm{kg} / \mathrm{day}$. Reduced but still significant protection from colitis could be measured when RDP58 was given orally at $1 \mathrm{mg} / \mathrm{kg} / \mathrm{day}$ or intraperitoneally at $5 \mathrm{mg} / \mathrm{kg} /$ day (data not shown).

Macroscopic examination after six days of DSS treatment disclosed atrophied, thin walled, and severely bleeding colons (fig 2). In contrast, the colons from DSS treated mice undergoing RDP58 therapy appeared relatively normal. This last finding provided qualitative yet compelling evidence substantiating a protective effect for RDP58 in this colitis model system. 


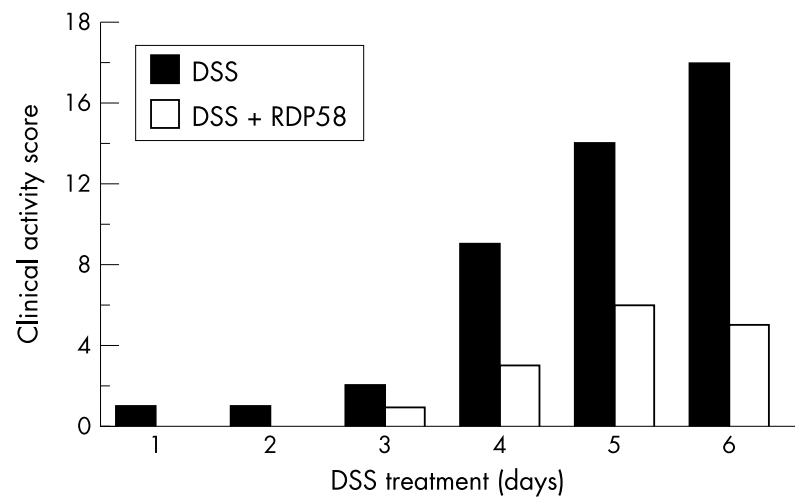

Figure 1 Orally administered RDP58 reduces the severity of clinical symptoms during acute DSS colitis. Severity of colitis in DSS treated mice $(n=4)$ and DSS treated mice receiving RDP58 $(n=4)$. Results are expressed as the mean clinical activity scores for each group. Control groups included mice kept on regular drinking water and mice receiving regular water and given RDP58 by gavage. A higher value indicates more severe disease. Control groups including those receiving RDP58 in the absence of DSS treatment had a clinical activity scores between 0 and 1 (data not shown). The data shown are representative of three separate experiments.

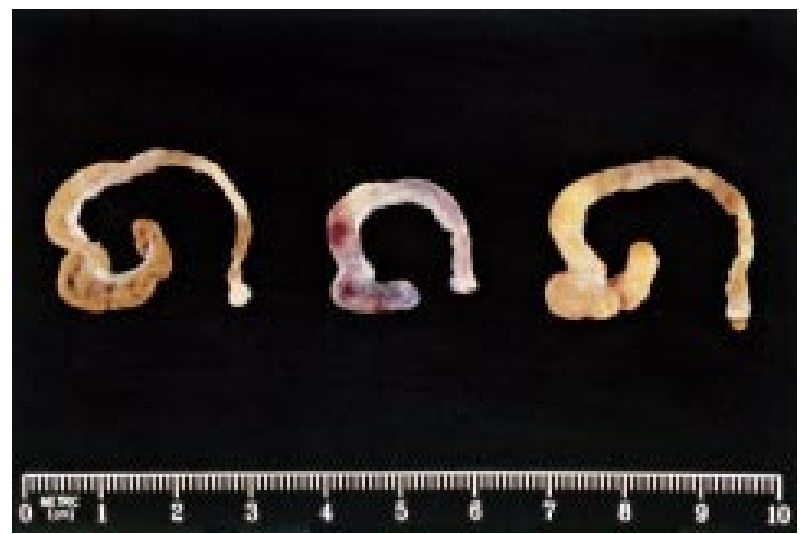

Figure 2 RDP58 dramatically lessens macroscopic evidence of DSS induced colonic damage. Representative colon from a control untreated mouse (left), a mouse fed DSS for six days (middle), and from a DSS treated mouse given RDP58 (right). The colon from DSS treated mice showed evidence of atrophy and profuse bleeding. In contrast, the colon from DSS treated mice receiving RDP58 remained relatively normal.

\section{Effect of orally administered RDP58 on the histological} features of acute DSS colitis

The colons of mice fed DSS in drinking water develop a well established temporal sequence of histopathological events, including crypt distortion, shortening, and drop out, occurring in parallel with an emerging inflammatory response. ${ }^{18}{ }^{19}$ In DSS colitis pronounced inflammation is a rather late event that follows histological evidence of tissue damage, suggesting that DSS may be directly toxic to colonic epithelial cells. ${ }^{23}$ It is important to note here that our histological analysis was thorough and included examination of entire colons obtained from mice used in at least three independent experiments. The colons from mice treated with DSS for six days showed extensive crypt drop out, ulceration, and a mild to intermediate acute inflammation consisting mostly of neutrophils (fig 3A). In contrast, the colon architecture in similarly treated mice undergoing RDP58 therapy appeared relatively normal, showing only mild evidence of crypt distortion, widening, and inflammation (fig 3A). Colon sections were used to measure crypt damage using an established scoring system..$^{21}$ The ability of RDP58 to block tissue destruction characteristic of DSS induced colitis was clearly demonstrated (fig 3B).
A
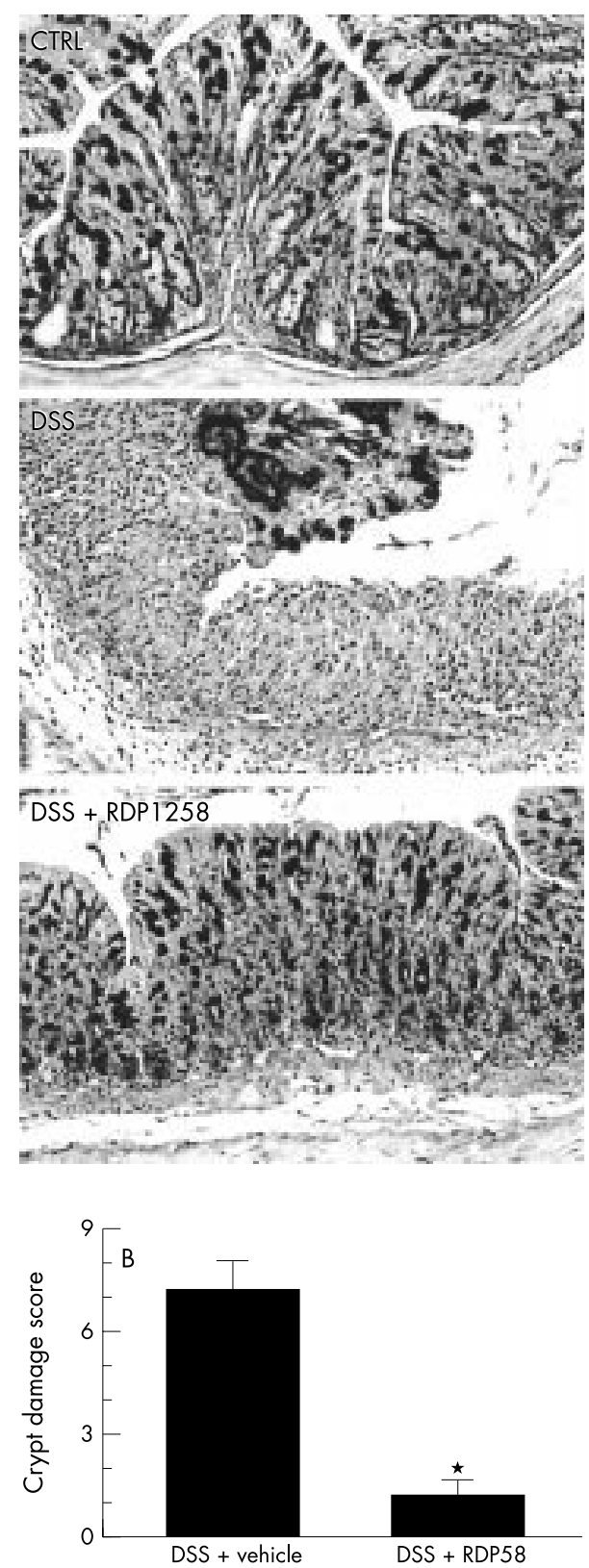

Figure 3 Histological presentation of colitis in DSS treated mice and protective effect of orally administered RDP58 (Allotrap 1258). (A) RDP58 preserves the architecture and minimises ulceration of the colon in DSS treated mice. Representative histology from the colon of a control untreated mouse (top panel), a mouse fed DSS for six days (middle panel), and from a DSS treated mouse given RDP58 (bottom panel). Original magnifications $\times 200$. (B) Quantitative analysis of crypt damage. The crypt damage score is described in "Materials and methods" and by Boismenu and Chen ${ }^{20} .{ }^{*} p<0.0001$ compared with DSS treated mice.

\section{RDP58 inhibits colonic production of TNF in DSS treated} mice

RDP58 is a potent inhibitor of TNF when tested in several in vivo and cell culture assays. ${ }^{14}$

Using reverse transcriptase-polymerase chain reaction (RTPCR), we observed increased TNF mRNA expression within 48 hours after the start of DSS treatment, with peak expression at around day 6 (fig 4A). A partial but significant reduction in TNF mRNA levels was detected in the colon of DSS treated mice undergoing RDP58 therapy (fig 4A). TNF protein 

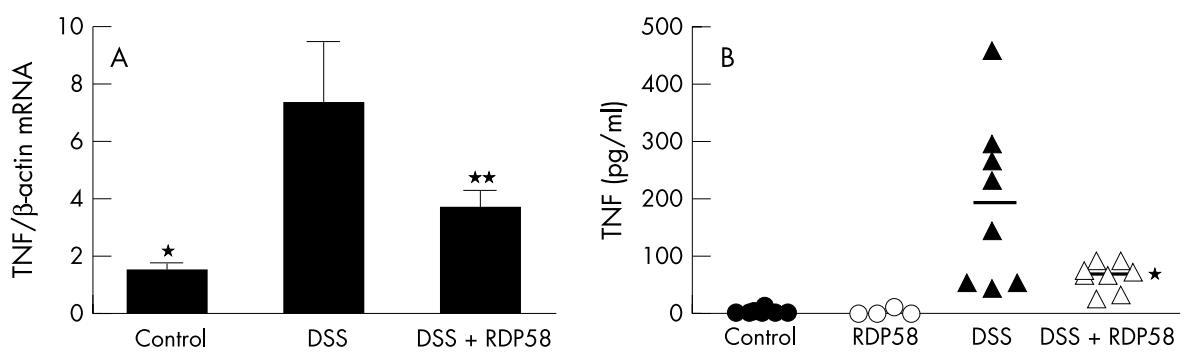

Figure 4 RDP58 inhibits TNF production in the colon of DSS treated mice. (A) TNF mRNA expression was evaluated by RT-PCR as described in "Materials and methods", and the data were measured with a fluorescence imager (Molecular Dynamics, CA). * $p<0.05$ compared with control mice and ${ }^{* *} p<0.005$ when compared with DSS treated mice. (B) TNF protein expression was measured from 18 hour culture supernatants of colon biopsy specimens as described in "Materials and methods". * $p<0.05$ when compared with DSS treated mice. Original magnification $\times 200$.

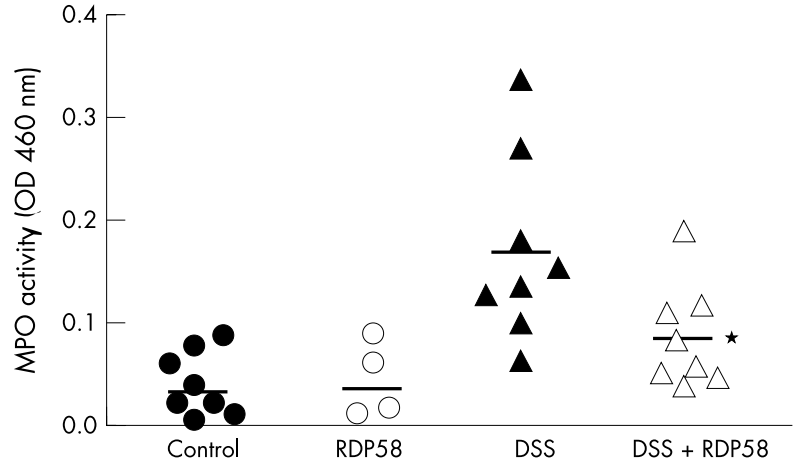

Figure 5 RDP58 reduces neutrophil infiltration in the colon of DSS treated mice. Tissue myeloperoxidase content was measured from colon samples removed from mice killed six days after initiation of DSS treatment as described in "Materials and methods". " $p<0.05$ compared with DSS treated mice. Comparison of values between DSS treated mice given RDP58 and control mice showed no significant differences.

production was assessed using cultured colon biopsy specimens. TNF in supernatants was measured by ELISA after a 12 hour culture period. Colon segments from DSS treated mice produced about 40-fold higher amounts of TNF than segments from normal control animals. In contrast, colon segments from DSS treated animals undergoing RDP58 therapy produced only about 10 times more TNF than biopsy specimens from normal animals (fig 4B). Thus, RDP58 effectively down regulated TNF protein overproduction associated with acute DSS colitis.

\section{RDP58 reduces neutrophil infiltration into the colon of DSS treated mice}

Neutrophils can produce significant amounts of TNF and are a major component of the cellular infiltrate in the colon of DSS treated mice. ${ }^{24}$ Therefore, lower TNF levels in colons of DSS treated mice undergoing RDP58 therapy may be due to reduced neutrophil emigration. Neutrophils in colonic tissue can be detected through MPO activity measurements. ${ }^{24}$ Consistent with previous findings, ${ }^{24}$ increased MPO activity (sixfold increase) was seen on day 6 of DSS treatment (fig 5). In contrast, significantly lower MPO levels (a twofold increase) were found in DSS treated mice undergoing RDP58 therapy (fig 5). The slightly raised level of MPO activity in DSS treated mice receiving RDP58 relative to control mice not receiving DSS was not significant $(\mathrm{p}>0.05)$. Thus, our results indicate that RDP58 therapy can markedly reduce neutrophil accumulation within the colon of DSS treated mice.

\section{Effect of RDP58 on colonic epithelial cell proliferation and death}

For the measurement of colonic epithelial cell proliferation, mice undergoing DSS treatment were injected intraperito-

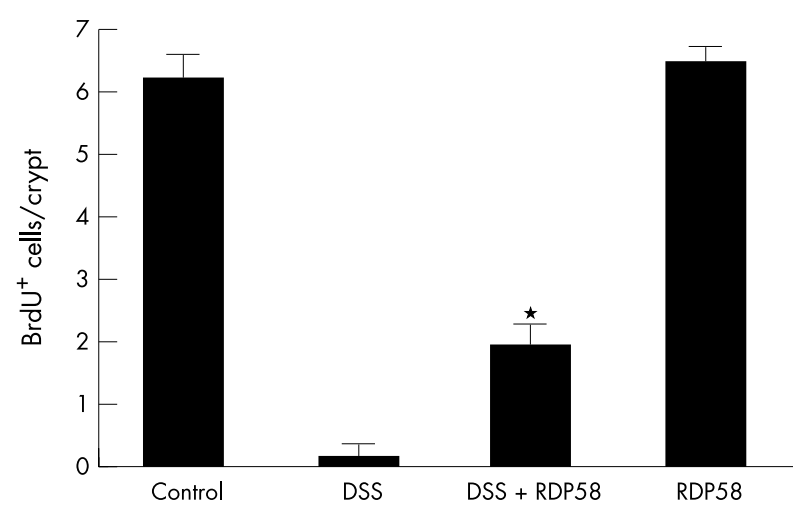

Figure 6 RDP58 preserves colonic epithelial cell proliferation in DSS treated mice. Epithelial cell proliferation was measured by in vivo BrdU administration as described in "Materials and methods". ${ }^{*} p<0.01$ compared with DSS treated mice.

neally with the DNA precursor analogue BrdU 24 hours before they were killed. Consistent with previous observations, ${ }^{25}$ the number of proliferating epithelial cells per crypt after six days of DSS treatment was reduced by more than $90 \%$ compared with control untreated mice (fig 6). Significantly more proliferating $\mathrm{BrdU}^{+}$epithelial cells (10-fold) were found in crypts of DSS treated mice undergoing RDP58 therapy (fig 6). However, the number of proliferating cells in these animals was significantly lower than in control mice not exposed to DSS, indicating that RDP58 only partially preserved the normal proliferative potential of colonic epithelial cells in DSS treated mice. In addition, these experiments showed that RDP58 has no obvious mitogenic or inhibitory effect on the proliferation of colonic epithelial cells in normal healthy animals.

The inhibitory effect of DSS on epithelial cell proliferation might be due to an increased rate of colonic epithelial cell death. This possibility was investigated using a TUNEL assay that measures DNA fragmentation, a late event in cell death by apoptosis. In addition to becoming TUNEL positive, cells undergoing apoptosis are characterised by features such as pyknotic nuclei and chromatin condensation that can be recognised histologically within morphologically intact cells. Few, if any, apoptotic cells were detectable in the colon of control mice not subjected to DSS treatment (fig 7). In contrast, a large number of colonic epithelial cells undergoing apoptosis were seen in DSS treated animals (fig 7). This effect could be detected as early as two days after the start of DSS treatment but was most dramatic on day 6. Strikingly, the colon of DSS treated mice concomitantly receiving RDP58 contained relatively few apoptotic epithelial cells, the majority of cells undergoing apoptosis being located in the lamina propria (fig 7). Thus, RDP58 effectively blocked or delayed DSS mediated colonic epithelial cell death. 

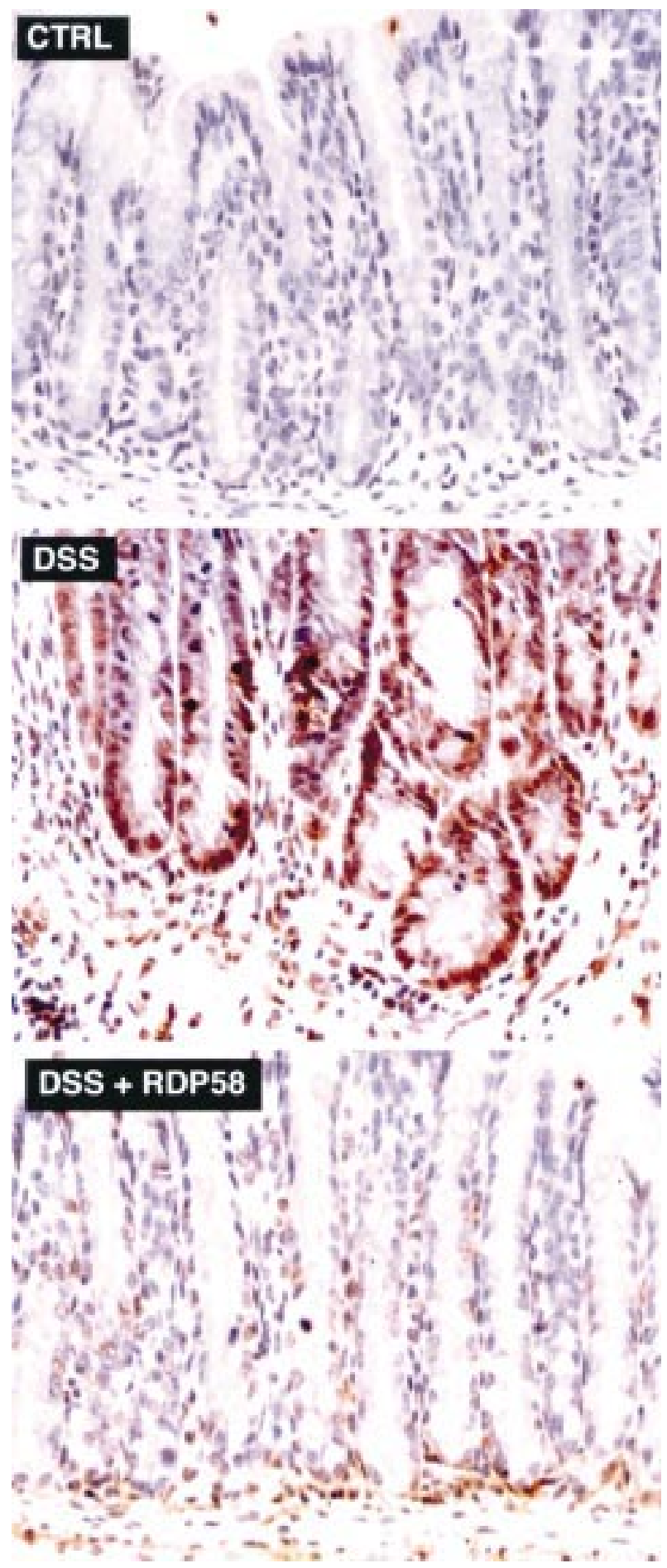

Figure 7 RDP58 blocks colonic epithelial cell apoptosis in DSS treated mice. Apoptosis was evaluated by the TUNEL assay as described in "Materials and methods". Representative TUNEL stained sections from the colon of a control untreated mouse (top panel), a mouse fed DSS for six days (middle panel), and from a DSS treated mouse given RDP58 (bottom panel). Original magnifications $\times 200$.

\section{DISCUSSION}

New drugs and treatment options are needed to prevent and/or treat IBD. Our interest in evaluating RDP58 as a potential therapeutic agent for IBD stems from its identification as a new small molecular weight TNF inhibitor operating posttranscriptionally ${ }^{14}$ and from the pivotal importance of TNF in the pathophysiology of IBD. ${ }^{116-31}$ Moreover, the resistance of D-isomer peptides such as RDP58 to proteases suggested that this drug might be effective when given orally. In addition, pharmacokinetic studies in mice, dogs, and non-human primates demonstrated that RDP58 is not bioavailable and acts locally. ${ }^{17}$ These features are desirable for the treatment of IBD. Currently available TNF inhibitors are mostly large molecular weight, protease sensitive proteins that require systemic administration.

The DSS murine colitis model system was exploited as an established general prototype of the biochemical and molecular events that can lead to intestinal tissue damage. The histological aspects of intestinal damage in DSS induced colitis share many similarities with those seen in patients affected by IBD and, in particular ulcerative colitis. ${ }^{18} 1922$ As described previously, DSS was found to induce alterations in crypt architecture, ulceration, and neutrophil infiltration in a highly reproducible temporal sequence. ${ }^{18} 19$ Interaction of DSS with epithelial cells, macrophages, and lamina propria cells has been described. ${ }^{23}{ }^{33}$ Lymphocytes do not appear to have an essential role in disease induction in this model system since SCID mice were found to be susceptible to DSS colitis. ${ }^{23}$ Thus, the overall toxic effects of DSS are believed to result from a direct interaction with epithelial cells as well as from the ability of this chemical to modulate the biological activities of macrophages and other potentially inflammatory cells. The contribution of inflammatory cells to DSS colitis was highlighted by the demonstration that prophylactic treatment with anti-ICAM mAb reduced colonic damage. ${ }^{34}$

A pathogenic role for TNF in acute and chronic DSS colitis can be inferred from the observed raised levels of TNF (this study, Krawisz et al, ${ }^{22}$ Murthy et $\mathrm{al}^{27}$ ) as well as from the beneficial effects obtained by using anti-TNF mAb therapy alone or in combination with the TNF release inhibitor pentoxifylline. ${ }^{27} 2935$ However, other investigators have reported contradictory data about the effects of antibody mediated TNF neutralisation in DSS colitis, with positive effects during chronic disease and no or negative effects during acute disease. ${ }^{28}{ }^{29}$ These discrepancies may be accounted for by the particular anti-TNF antibody used, dosage, and other variables in treatment protocols. ${ }^{27}{ }^{30}$ None the less, raised colonic TNF expression has been detected as early as one day after the start of DSS treatment, with peak production occurring between day 5 and day $7 .{ }^{23}{ }^{24}$

We determined that TNF production was severely inhibited in DSS treated mice receiving RDP58. This effect on TNF expression was most clearly seen at the protein level, but mRNA levels were also reduced. This finding is seemingly at odds with a previous study showing that in a cell culture system RDP58 modulates TNF protein expression without effecting mRNA levels. ${ }^{14}$ Both findings, however, could be easily reconciled if RDP58 treatment reduced the numbers of TNF mRNA expressing cells present within the colons of DSS fed mice. In support of this hypothesis, we have shown that neutrophils, a known TNF mRNA source, are less numerous within the colons of DSS fed mice that received RDP58.

As described by us in this report and by others, ${ }^{25}$ few enterocytes retain the ability to incorporate BrdU into DNA past the first few days of DSS treatment. However, a small but significant number of enterocytes in mice receiving RDP58 could be shown to incorporate BrdU after six days of DSS treatment. More strikingly, RDP58 strongly protected colonic epithelial cells from DSS induced cell death based on TUNEL and histological observations of apoptotic features. This may be the result of RDP58 mediated TNF inhibition because signals conveyed by TNF through the TNF receptor I (p55) can induce activation of the apoptotic cell death pathway in epithelial cells. ${ }^{36}{ }^{37}$

The inhibitory effect of RDP58 on TNF protein production may be sufficient to explain its ability to protect against DSS induced colitis. However, it is important to note that besides inhibition of TNF production, RDP58 displays additional activities. In particular, RDP58 was shown to inhibit the 
production of IFN $\gamma$ and IL12 and to induce the expression of HO- $1 .{ }^{14-17}$ Little is known about RDP58 mediated inhibition of IFN $\gamma$ and IL12. Recently, the RDP58 mediated inhibition of TNF production was shown to occur at the translational level. ${ }^{14}$ Up regulation of $\mathrm{HO}-1$ protein expression during RDP58 therapy appears to be due to weak inhibition of cellular HO-1 activity by RDP58 and subsequent up regulation of HO- 1 gene expression. ${ }^{38}$

There is abundant evidence that raised HO-1 levels correlate with resistance to stress, particularly in cases of hyperoxia, ischaemia, and inflammation. ${ }^{38-40}$ Therefore, both activitiesinhibition of cytokine production and up regulation of HO-1 expression-may contribute to the anti-inflammatory activity of RDP58 seen in our study.

The ability of RDP58 to alleviate symptoms of DSS colitis suggests that this drug holds promise as a treatment for human IBD. In addition, RDP58 may help to enhance the therapeutic efficacy of conventional drugs used to treat IBD. The usefulness of RDP58 given alone or in combination therapy should be testable in the DSS colitis model as well as in other experimental IBD model systems. ${ }^{17}$ Thus, additional continuing studies will help to further define the value of RDP58 as a research tool and as a clinical agent to treat IBD and potentially other disorders characterised by inflammation, tissue destruction, and TNF overproduction.

\section{ACKNOWLEDGEMENTS}

This work was supported by SangStat Medical Corporation, and by a Crohn's and Colitis Foundation of America (CCFA) First Award grant and NIH grant AI40616 to RB. YC was the recipient of a post-doctoral fellowship from the CCFA. This is manuscript 12507-IMM from The Scripps Research Institute.

\section{Authors' affiliations}

R Boismenu, Y Chen, K Chou, A El-Sheikh, Department of Immunology, The Scripps Research Institute, La Jolla, California 92037, USA

R Buelow, SangStat, Fremont, California 94555, USA

Correspondence to: Dr R Boismenu, Repligen Corporation, 41 Seyon Street, Building No 1, Suite 100, Waltham, MA 02453, USA rboismenu@repligen.com

\section{REFERENCES}

1 Fiocchi C. Inflammatory bowel disease: etiology and pathogenesis. Gastroenterology 1998;115:182.

2 MacDonald TT, Hutchings P, Choy MS, Murch S, Cooke A. Tumour necrosis factor-alpha and interferon-gamma production measured at the single cell level in normal and inflamed human intestine. Clin Exp Immunol 1990:81:301.

3 Braegger CP, Nicholls S, Murch SH, Stephens S, MacDonald TT. Tumor necrosis factor alpha in stool as a marker of intestinal inflammation. Lancet 1992;339:89

4 Murch SH, Braegger CP, Walker-Smith JA, MacDonald TT. Localisation of tumor necrosis factor alpha by immunochemistry in chronic inflammatory bowel disease. Gut 1993:34:1705.

5 Breese EJ, Michie CA, Nicholls SW, Murch SH, Williams CB, Domizio PWS, et al. Tumor necrosis alpha-producing cells in the intestinal mucosa of children with inflammatory bowel disease. Gastroenterology 1994: 106: 1455.

6 van Deventer SJ. Tumour necrosis factor and Crohn's disease. Gut 1997;40:443

7 van Dullemen HM, van Deventer SJH, Hommes DW, Bijl HA, Tytgat GNJ, Woody J. Treatment of Crohn's disease with anti-tumor necrosis factor chimeric monoclonal antibody (cA2). Gastroenterology 1995; 109: 129

8 Stack WA, Mann SD, Roy AJ, Heath P, Sopwith M, Freeman J, et al. Randomized controlled trial of CDP571 antibody to tumor necrosis factor-alpha in Crohn's disease. Lancet 1997;349:521.

9 Targan SR, Hanaver SB, van Deventer SJ, Mayer L, Present DH, Braakman T, et al. A short-term study of chimeric monoclonal antibody cA2 to tumor necrosis factor alpha for Crohn's disease. N Engl J Med 1997;337:1029.

10 Plevy SE, Landers CJ, Prehn J, Carramanzana NM, Deem RL, Shealy D, et al. A role for TNF- $\alpha$ and mucosal T helper-1 cytokines in the pathogenesis of Crohn's disease. J Immunol 1997;159:6267.

11 Papadakis KA, Targan SR. Role of cytokines in the pathogenesis of inflammatory bowel disease. Annu Rev Med 2000;51:289.
12 Baert FJ, D'Haens G, Peeters M, Hiele MI, Schaible TF, Shealy D, et al. Tumor necrosis factor $\alpha$ antibody (infliximab) therapy profoundly down-regulates the inflammation in Crohn's ileocolitis. Gastroenterology 1999; 1 16:22.

13 D'Haens G, van Deventer S, van Hogezand C, Kothe DC, Baert F, Braakman T, et al. Endoscopic and histological healing with infliximab anti-tumor necrosis factor antibodies in Crohn's disease: a European multicenter trial. Gastroenterology 1999;116:1029.

14 Iyer S, Kontoyiannis D, Chevrier D, Woo J, Mori N, Cornejo M, et al. Inhibition of tumor necrosis factor mRNA translation by a rationally designed immunomodulatory peptide. J Biol Chem 2000;275:17051.

15 Grassy G, Calas B, Yasri A, Lahana R, Woo J, lyer S, et al. Computer-assisted rational design of immunosuppressive compounds. Nature Biotechnol 1998;16:748.

16 Cuturi MC, Cristoph F, Woo J, lyer S, Brouard S, Heslan JM, et al. RDP1258, a new rationally designed immunosuppressive peptide, prolongs allograft survival in rats: analysis of its mechanism of action. Mol Med 1999:5:820.

17 lyer, S, Lahana R, Buelow R. Rational design and development of RDP58. Current Pharmaceutical Design 2002;8:99

18 Okayasu I, HatakeyamaS, Yamada M, Ohkusa T, Inagaki Y, Nakaya R. A novel method in the induction of reliable experimental acute and chronic ulcerative colitis in mice. Gastroenterology 1990;98:694.

19 Cooper HS, Murthy SNS, Shah RS, Sedergran DJ. Clinicopathologic study of dextran sulfate sodium experimental murine colitis. Lab Invest 1993;69:238.

20 Boismenu R, Chen Y. Insights from mouse models of colitis. J Leukoc Bio 2000;67:267.

21 Dieleman LA, Palmen M, Akol H, Bloemena E, Pena AS, Meuwissen SG, et al. Chronic experimental colitis induced by dextran sulphate sodium (DSS) is characterized by Th1 and Th2 cytokines. Clin Exp Immunol 1998; 114:385.

22 Krawisz JE, Sharon P, Stenson WF. Quantitative assay for acute intestinal inflammation based on myeloperoxidase activity. Gastroenerology 1984;87:1344.

23 Dieleman LA, Ridwan BU, Tennyson GS, Beagley KW, Bucy RP, Elson CO. Dextran sulfate sodium-induced colitis occurs in severe combined immunodeficient mice. Gastroenterology 1994;107:1643.

24 Tomoyose $\mathbf{M}$, Mitsuyama K, Ishida H, Toyonaga A, Tanikawa K. Role of interleukin-10 in murine model of dextran sulfate sodium-induced colitis. Scand J Gastroenterol 1998;33:435

25 Tessner TG, Cohn SM, Schloemann S, Stenson WF. Prostaglandins prevent decreased epithelial cell proliferation associated with dextran sodium sulfate injury in mice. Gastroenterology 1998;1 15:874.

26 Beutler BA. The role of tumor necrosis factor in health and disease. J Rheumatol 1999:26:16.

27 Murthy S, Cooper HS, Yoshitake H, Meyer C, Meyer CJ, Murthy NS. Combination therapy of pentoxyfylline and TNF alpha monoclonal antibody in dextran sulphate-induced mouse colitis. Aliment Pharmaco Ther 1999;13:251.

28 Olson AD, DelBuono EA, Bitar KN, Remick DG. Antiserum to tumor necrosis factor and failure to prevent murine colitis. J Pediatr Gastroenterol Nutr 1995;21:410.

29 Kojouharoff G, Obermeier HF, Mannel DN, Andus T, Scholmerich A Gross V, et al. Neutralization of tumour necrosis factor (TNF) but not IL-1 reduces inflammation in chronic dextran sulfate sodium-induced colitis in mice. Clin Exp Immunol 1997; 107:353.

30 Videla S, Garcia-Lafuente A, Antolin M, Vilaseca J, Guarner F, Crespo $\mathrm{E}$, et al. Antitumor necrosis factor therapy in rat chronic granulomatous colitis: critical dose-timing effects on outcome. J Pharmacol Exp Ther 1998;287:854

31 Sandborn WJ, Hanauer SB. Antitumor necrosis factor therapy for inflammatory bowel disease: a review of agents, pharmacology, clinical results, and safety. Inflamm. Bowel Dis 1999.5:119.

32 Elson CO, Sartor RB, Tennyson GS, Riddell RH. Experimental models of inflammatory bowel disease. Gastroenterology 1995;109:1344.

33 Kitajima S, Takuma S, Morimoto M. Tissue distribution of dextran sulfate sodium (DSS) in the acute phase of murine DSS-induced colitis. J Vet Med Sc. 1999;61:67.

34 Taniguchi T, Tsukada H, Nakamura H, Kodama M, Fukuda K, SaitoY, et al. Effects of the anti-ICAM-1 monoclonal antibody on dextran sodium sulphate-induced colitis in rats. J Gastroenterol Hepatol 1998;13:945.

35 Neurath MF, Fuss I, Pasparakis M, Alexopoulou L, Haralambous S, Meyer zum Buschenfelde K, et al. Predominant pathogenic role of tumor necrosis factor in experimental colitis in mice. Eur J Immuno 1997:27:1743.

36 Steller H. Mechanisms and genes of cellular suicide. Science $1995 ; 267: 1445$

37 Salvesen GS, Dixit VM. Caspases: intracellular signaling by proteolysis.Cell 1997;91:443.

38 Maines MD. The heme oxygenase system: a regulator of second messenger gases. Annu Rev Pharmacol Toxicol 1997;37:517.

39 Willis D, Moore AR, Frederick R, Willoughby DA. Heme oxygenase: a novel target for the modulation of the inflammatory response. Nature Med 1997;2:87.

40 Otterbein LE, Sylvester SL, Choi AMK. Hemoglobin provides protection against lethal endotoxemia in rats: the role of heme oxygenase-1. Am J Resp Cell Mol Biol 1995; 13: 595. 